\title{
(Auto)biografía de un fracaso: el pintor-funcionario Adolfo Moreno Sanjuán a través de sus memorias
}

\section{(Auto)biography of a Failure; the Painter and Civil Servant Adolfo Moreno Sanjuán Through his Memories}

Artículo recibido el 26 de marzo de 2020; devuelto para revisión el 20 de noviembre de 2020; aceptado el I2 de enero de 202I; https://doi.org/IO.2220I/iie.I8703062e.202I.II9.2757

Pablo Allepuz García Consejo Superior de Investigaciones Científicas (csic), Instituto de Historia, pablo.allepuz@cchs.csic.es, https://orcid.org/oooo-0oo3-3I62-38IX

Líneas de investigación Historia del arte; autobiografía; vanguardias; estudios de memoria.

Lines of research History of art; autobiography; avant-garde; memory studies.

Publicación más relevante “¿Dalí joven, Dalí genial? Mitos y leyendas de artista en La vida secreta de Salvador Dali (1942)”, Goya. Revista de Arte, núm. 370 (2020): 48-63.

Resumen Adolfo Moreno Sanjuán (I888-1965) completó su formación en la Escuela Especial de Pintura, Escultura y Grabado de Madrid, pero recién egresado aceptó un puesto administrativo en el Ministerio de Fomento. En adelante su trabajo creativo quedaría limitado a un par de admisiones en las Exposiciones Nacionales, el consuelo insuficiente de los Salones de Otoño y la participación esporádica en eventos menores. El cotejo de sus memorias inéditas con diversas fuentes de archivo y hemeroteca, por una parte, permite reconstruir su larga trayectoria y completar la imagen que tenemos sobre el sistema del arte del momento, pues ofrece una perspectiva frecuentemente escamoteada por los relatos hegemónicos. Por otra parte, dentro del contexto específico de la autobiografía de artista, el análisis de los discursos desplegados en su texto permite problematizar este tipo de egodocumento y proponer un contramodelo de representación tanto identitario como historiográfico.

Palabras clave Historia del arte; autobiografía; artista; franquismo; estudios culturales.

Abstract Adolfo Moreno Sanjuán (I888-1965) completed his education at the Escuela Especial de Pintura, Escultura y Grabado in Madrid, but soon after his graduation he accepted an administrative post in the Ministry of Economic Development. From then on his creative work 
was limited to a few admissions in National Exhibitions, the insufficient consolation of the Salones de Otoño and occasional participation in lesser events. The article presents a collation of his unpublished memoirs with diverse sources in archives and periodicals. This enables us, on the one hand, to reconstruct his long artistic career and to complete the image we have of the artistic establishment of the period, since it offers a perspective frequently buried beneath the hegemonic accounts. On the other hand, within the specific context of the artist's autobiography, a discourse analysis of the material provided by his text helps us to problematize this kind of "ego-document" and to propose a countermodel of both historiographic and identity representation.

Keywords Art history; autobiography; artist; Francoism; cultural studies. 
DOI: https://doi.org/10.22201/iie.18703062e.2021.119.2757

PABLO ALLEPUZ GARCÍA

INSTITUTO DE Historia, CSIC, ESPAÑA

\section{(Auto)biografía de un fracaso: el pintor-funcionario Adolfo Moreno Sanjuán a través de sus memorias}

$\mathrm{L}$ a escritura de la vida, en general, así como la biografía y la autobiografía, en particular, han supuesto durante siglos un ámbito de exclusividad para privilegiados, y sólo recientemente se han replanteado tales categorías para posibilitar la inclusión de los subalternos en el flujo de la historia; "digo historia", con Isidoro L. Lapuya, y contra Thomas Carlyle, "pensando en que ésta no se compone solamente de la narración de hechos transcendentales, realizados por grandes hombres", sino que "valen también mucho los detalles de la vida media, de los hombres que iban camino de la cumbre y no llegaron a ella”. 'A partir de los años sesenta del siglo xx, buena parte de la historiografía internacional ha redoblado los esfuerzos por completar un cambio de paradigma hacia enfoques como la historia desde abajo o la microhistoria, que dieran cuenta de tantos y tantos episodios olvidados: siempre y cuando no se caiga en el pintoresquismo o el localismo fútiles, observar lo minúsculo — lo aparentemente insignificante — puede revelarse de la mayor importancia y contribuir a desjerarquizar las visiones del pasado. ${ }^{2}$

I. Isidoro L. Lapuya, La bohemia española en París a fines del siglo pasado. Desfile anecdótico de politicos, escritores, artistas, prospectores de negocios, buscavidas y desventurados (Sevilla: Renacimiento, 200I), 2I; Thomas Carlyle, Sobre los héroes. El culto al héroe y lo heroico en la historia (Sevilla: Athenaica Ediciones, 2017).

2. Véase Justo Serna y Anaclet Pons, Microhistoria. Las narraciones de Carlo Ginzburg (Granada: Comares, 2019) y Timothy G. Ashplant, "Life Writing 'From Below' in Europe: Introduction", European Journal of Life Writing, núm. 7 (2018): I-9. 


\section{DOI: https://doi.org/10.22201/iie.18703062e.2021.119.2757}

IO8

PABLO ALLEPUZ GARCÍA

La disciplina de la historia del arte ha puesto en práctica algunas de esas aportaciones mediante la asimilación de corrientes sociológicas, feministas o decoloniales, entre otras, pero la vigencia del criterio específico de "calidad" mantiene prácticamente inalterables los fundamentos de sus discursos hegemónicos, ya sean historiográficos, museísticos o comerciales: si bien se han ido incorporando manifestaciones otrora minusvaloradas, lo cierto es que el proceso de recuperación de las mismas suele replicar esa lógica patrimonialista de la excepcionalidad; es decir, los casos marginales van adaptándose a la norma hasta encajar en el canon preestablecido en lugar de reivindicar su otredad radical para ponerlo en crisis, todo lo cual contribuye en última instancia a la paradoja de su legitimación. ${ }^{3}$

Esto resulta en especial evidente en el tratamiento del fracaso, a menudo pura omisión y la mayoría de ocasiones un mero obstáculo provisional que el protagonista debe superar para convertirse en héroe: más allá del fracaso como condición del creador maldito ${ }^{4}$ o como procedimiento plástico de ensayo y error, ${ }^{5}$ apenas se han prodigado estudios sobre la verdadera relevancia de un fenómeno que ha constituido siempre el destino más probable para cualquier aspirante a artista. ${ }^{6}$ Así pues, la gran cantidad de alumnos matriculados en las Escuelas de Bellas Artes o de Artes y Oficios que no sobresalieron por su talento, de egresados que no consiguieron consolidar un estudio ni fijar clientela, de candidatos que fueron rechazados sistemáticamente en las Exposiciones Nacionales de Bellas Artes, de expositores en los Salones de Otońo u otros eventos de menor prestigio que no generaron ninguna repercusión, de trabajadores de todo tipo que abandonaron la profesión para ganarse la vida... carecen de reflejo en las representaciones científicas del pasado.

3. Véase Gabriele Guercio, Art as Existence. The Artist's Monograph and Its Project (Cambridge: MIT Press, 2006); Estrella de Diego, "En torno al concepto de calidad y otras falsedades del discurso impuesto", en Carlos González Navarro, comp., Invitadas. Fragmentos sobre mujeres, ideología y artes plásticas en España (I833-I93I) (Madrid: Museo del Prado, 2020), 25-39.

4. Véase Jean-Yves Jouannais, Infamie (París: Hazan, 1995) y Francisco Calvo Serraller, La novela del artista. El creador como héroe de la ficción contemporánea (Madrid: Fondo de Cultura Económica, 2013).

5. Véase Lisa Le Feuvre, ed., Failure (Cambridge: Whitechapel Gallery/ mit Press, 20Io).

6. Prácticamente la única iniciativa de relieve en este sentido ha sido "Towards a Loser's Art History: Artistic Failure in the Long Nineteenth Century”, Conference Session, IO2 ${ }^{\circ}$ College Art Association Anual Conference, Chicago, I2 de febrero de 2014. 
En efecto, la realidad artística solía ser bastante diferente de la que termina conformando el relato de la historia del arte con mayúsculas y, como ya afirmó Jaime Brihuega, la atención excesiva a las propuestas vanguardistas en España desemboca en un correlato poco ajustado a su contexto: ${ }^{7}$ por cada artista de vanguardia que destaca en el panorama internacional, hay un buen puñado de artistas de retaguardia que imitan las novedades sin demasiada solvencia o que se mantienen anclados en concepciones reaccionarias; por cada artista que se incorpora al grupo de moda en la capital cultural del momento, hay ciertas camarillas de provincias que imponen su cuota de poder y cuestionan cualquier irrupción de modernidad; por cada artista que logra hacerse un nombre entre los críticos e historiadores, hay una lista interminable de aquellos que fracasan en su intento y lo pierden para siempre. ${ }^{8}$

Adolfo Moreno Sanjuán sin duda pertenece a los segundos. La suya es una biografía de vocación no cumplida, de ambición muy moderada, de empeño derrochado en vano, de conformismo, desencanto, resignación... en suma, de todo lo que se descarta de inmediato al reconstruir un periodo histórico-artístico; pero tampoco alcanza el estatuto de heterodoxo o "anormal", pobre de solemnidad ni enfermo mental, ni represaliado de guerra, ni exiliado político, ni sufría discriminación por su género biológico, orientación sexual, condición racial o diversidad funcional..., lo cual le habría podido valer una consideración diferente. No. El motivo de su perfil bajísimo hay que buscarlo precisamente en su acomodada posición del justo medio, ni tan singular en su obstinación como para sorprender por su obra, ni tan rebelde en su apatía como para fascinar por su personalidad: hombre sin atributos instalado en la mediocridad —áurea o no-, de manera muy significativa concluyó sus memorias calificando su pintura, y por extensión su propia vida, como "discreta". ${ }^{\text {10 }}$

$\mathrm{Al}$ seguir el hilo de estas memorias inéditas — debidamente contrastadas con material de archivo y hemeroteca-, las páginas siguientes darán cuenta de esa vida discreta: las preocupaciones cotidianas, la gestión de las expectativas personales, la escasez de oportunidades, la pugna con el servilismo del

7. Jaime Brihuega, Las vanguardias artísticas en España, I909-1936 (Madrid: Istmo, 198I), 22-33.

8. Sobre la importancia del nombre, véase el epígrafe "Naming: Canons, Acculturation, and Keeping Up with Readers", de Julie F. Codell, en The Victorian Artist. Artists' Life Writings in Britain, ca. I870-I9Io (Nueva York: Cambridge University Press, 2012), 24-29.

9. Michel Foucault, La vida de los hombres infames (La Plata: Altamira, 1996), I2I-I38.

Io. Adolfo Moreno Sanjuán, Memorias biográficas del pintor Adolfo Moreno Sanjuán, documento inédito conservado en colección particular, 1964, 56. 


\section{DOI: https://doi.org/10.22201/iie.18703062e.2021.119.2757}

IIO

PABLO ALLEPUZ GARCÍA

medio, las omisiones más que elocuentes... todo lo cual resulta perfectamente extrapolable a un amplio número de colegas. A diferencia de las vicisitudes de los considerados grandes genios, esta perspectiva microhistórica explica mucho mejor las dinámicas del sistema del arte durante la primera mitad del siglo xx en España y los límites de la construcción de la personalidad del artista al margen de los modelos narrativos ya institucionalizados. ${ }^{\text {II }}$

\section{La infancia en provincias: prefiguraciones de un fracaso anunciado}

Adolfo Moreno Sanjuán nació en Navas de San Juan (Jaén) el 24 de diciembre de I888, fruto único del matrimonio entre Silverio Moreno León y Adolfina Sanjuán Moreno, ${ }^{12}$ y creció en la cercana localidad de Castellar de Santisteban junto a la familia materna gracias a una permuta laboral de su padre con otro maestro de escuela. ${ }^{13}$ Allí pasaría su infancia y su adolescencia completas, momentos clave para el desarrollo de la personalidad de los que no queda más información que la aportada por él en su opúsculo autobiográfico: ${ }^{14}$ niño enfermizo y con un tumor blanco en la rodilla derecha que le acarrearía diversos problemas a lo largo de su vida, contrarrestó las inseguridades derivadas de su deficiencia física con una memoria visual prodigiosa y precoz, en virtud de la cual recitaba cuentos cortos, escribía palabras y reproducía ilustraciones antes incluso de haber aprendido a leer; "éstos fueron mis primeros indicios de

II. Véase Sandra Kisters, The Lure of the Biographical. On the (Self-)Representation of Modern Artists (Ámsterdam: Valiz, 2017).

I2. Archivo General del Ministerio de Transportes, Movilidad y Agenda Urbana, España (en adelante, Agmitma), Personal, leg. 606I, Partida de bautismo legalizada.

I3. La ascendencia materna hunde sus raíces en la Comarca del Condado desde su tatarabuelo Mariano Sanjuán Rico hasta la generación de su madre y sus tíos José y Enrique —-mellizos-, Mariano, Eloy y Herminia. Agradezco encarecidamente al cronista de Castellar - Jacinto Mercado Pérez- la ayuda que me ha prestado al compartir conmigo sus investigaciones genealógicas; así como el hecho de ponerme en contacto con un familiar lejano de Adolfo - Javier Sanjuán Rodríguez - gracias a quien ha sido posible esclarecer muchos de estos aspectos. Lamentablemente no parece haber descendientes directos de Adolfo y por tanto tampoco un archivo familiar del que nutrir esta investigación, lo cual tiene que ver a su vez con las dinámicas de desmemoria que afectan a los personajes marginales del relato dominante.

I4. Moreno Sanjuán, Memorias biográficas, I-8. Para la importancia de la infancia y la juventud en los relatos historiográficos sobre artistas, véase Ernst Kris y Otto Kurz, La leyenda del artista (Madrid: Cátedra, 2010), 3I-32. 
dibujante" —asume— "que quizás nacieron y se revelaron, así como mis otras facultades mentales, por mi incapacidad para moverme". ${ }^{\text {is }}$ El pequeño Adolfo sólo recibió educación reglada entre los diez y los doce ańos, primero por su precaria salud y negligencia de sus progenitores, después por cierre del colegio, de manera que el resto del tiempo lo pasó en casa atendiendo a las esporádicas lecciones a cargo de su padre, un cura, un médico y un farmacéutico, ejercitándose en el jardín o construyendo sus propios juguetes e ingenios mecánicos.

El desparpajo y el aplomo que derrochaba entonces en tales actividades, impropios para alguien tan joven, fueron dando paso paulatinamente a una timidez casi patológica por su complejo de inferioridad respecto a otros vecinos sanos y fornidos; buena parte de las veces infundada, pues a base de esfuerzo se sabía ya más audaz, más ágil, más informado y más noble que sus compañeros. El reconocimiento que de ellos obtenía por cada proeza deportiva o artística no sólo no le servía para mejorar su autoestima, sino que contribuía a la sobrevaloración de los demás en detrimento de sí mismo, hasta el punto de no ser capaz siquiera de intervenir en una conversación trivial:

tenía admiradores entre los de mi edad por mis defectuosos y desgraciados dibujos, pero yo envidiaba a otro chico, uno o dos años menor, que dibujaba con gran soltura, ¡cada cabeza de toro o el mismo completo!, ¡cada torero con su gorra y su capote!, ;y cada picador a caballo o estos separados! ${ }^{16}$

A pesar de todo, Adolfo continuó con sus trabajos manuales y dedicaba muchas horas a sus inquietudes plásticas: hacía retratos de personas conocidas, que su padre solía recoger para enseñarlos a parientes y amigos; imitaba en tamaño reducido — con lápices de colores - cuadros al óleo de paisajes que luego ampliaba con aportes fantásticos; o dibujaba de memoria la iglesia colegial y el portal de su casa, en vez de copiarlos del natural. Pero, siempre según su relato, no escapaba a la frustración: "nada me satisface pensando en aquellos toros, toreros y caballos, que dibuja mi amigo", "nadie me alienta ni dirige", porque "no hay en el pueblo quien se interese por el dibujo ni la pintura, ni que entien-

15. Moreno Sanjuán, Memorias biográficas, 2. Para la relación entre enfermedad y arte, así como entre melancolía y genialidad, véase Esperanza Guillén, El sufrimiento creativo. Textos intimos de artistas (Madrid: Minerva, 2018); o Rudolf Wittkower y Margot Wittkower, Nacidos bajo el signo de Saturno. Genio y temperamento de los artistas desde la Antigüedad hasta la Revolución francesa (Madrid: Cátedra, 2015), I00-130.

16. Moreno Sanjuán, Memorias biográficas, 4. 


\section{DOI: https://doi.org/10.22201/iie.18703062e.2021.119.2757}

da; y si alguno me dice algo acerca de mis dibujos, lo hace con sorna o chanza”. La incomprensión por sus inclinaciones era generalizada, especialmente en el seno familiar, y en todo caso planteaban para él una carrera corta de delineante, correos o aduanas... de ahí la atípica escena que rememora: "tengo diez y ocho [años] y un buen día me pregunta mi padre: ‘QQuieres ser pintor?' Le contesté que sí y al cabo de unos meses salgo de Castellar para hacerme pintor". ${ }^{17}$

\section{Etapa de formación en Madrid: primeras decepciones}

Adolfo llegó a Madrid en octubre de 1907, pero esos antecedentes geográficos, familiares y personales no habían quedado atrás. Sirva como ejemplo el simple hecho de plantarse en Madrid entrado octubre, justo un mes después de que se hubieran celebrado los exámenes oficiales de ingreso a la Escuela Especial de Pintura, Escultura y Grabado, cuando ya no había ningún margen de maniobra: poca gente del medio rural giennense podría haberle advertido al respecto, nadie de su entorno más cercano se informó debidamente del proceso de matrícula y él, a fin de cuentas un adolescente de provincias sin vocación definida, tampoco estaba al tanto de requisitos ni plazos. La consecuencia inmediata para el recién llegado sería un año completo desperdiciado a nivel formativo, toda vez que no fue capaz de formular una alternativa a la altura de sus necesidades.

Una de las escasas opciones que pergeńó para aprovechar ese tiempo libre fue el Museo de Reproducciones Artísticas del Casón del Buen Retiro, adonde acudían a copiar vaciados clásicos dibujantes de toda procedencia, clase, sexo y edad, pero su falta de experiencia en comparación con sus eventuales compañeros le produjo de nuevo una profunda vergüenza y buscó la evasión por múltiples vías: primero, refugiándose en el culto al cuerpo, y después, entregándose al cortejo de alguna "modistilla madrileńa"; en definitiva, estrenando el libertinaje anónimo que brinda la gran ciudad, siempre en perjuicio del aprendizaje plástico. "Mi vida en Madrid durante el curso 1907-1908 me dańó bastante", ${ }^{18}$ reconoce con cierto arrepentimiento. $\mathrm{Y}$ es que, llegado el momento de concurrir al dichoso examen de ingreso, no consiguió superarlo en ninguna de las dos convocatorias — ni septiembre ni febrero- y volvió a quedar fuera de la Escuela; esta vez sin ningún tipo de excusa burocrática, sino

17. Moreno Sanjuán, Memorias biográficas, 7-8.

I8. Moreno Sanjuán, Memorias biográficas, I5. 
DOI: https://doi.org/10.22201/iie.18703062e.2021.119.2757

(AUTO)BIOGRAFÍA DE UN FRACASO: EL PINTOR-FUNCIONARIO

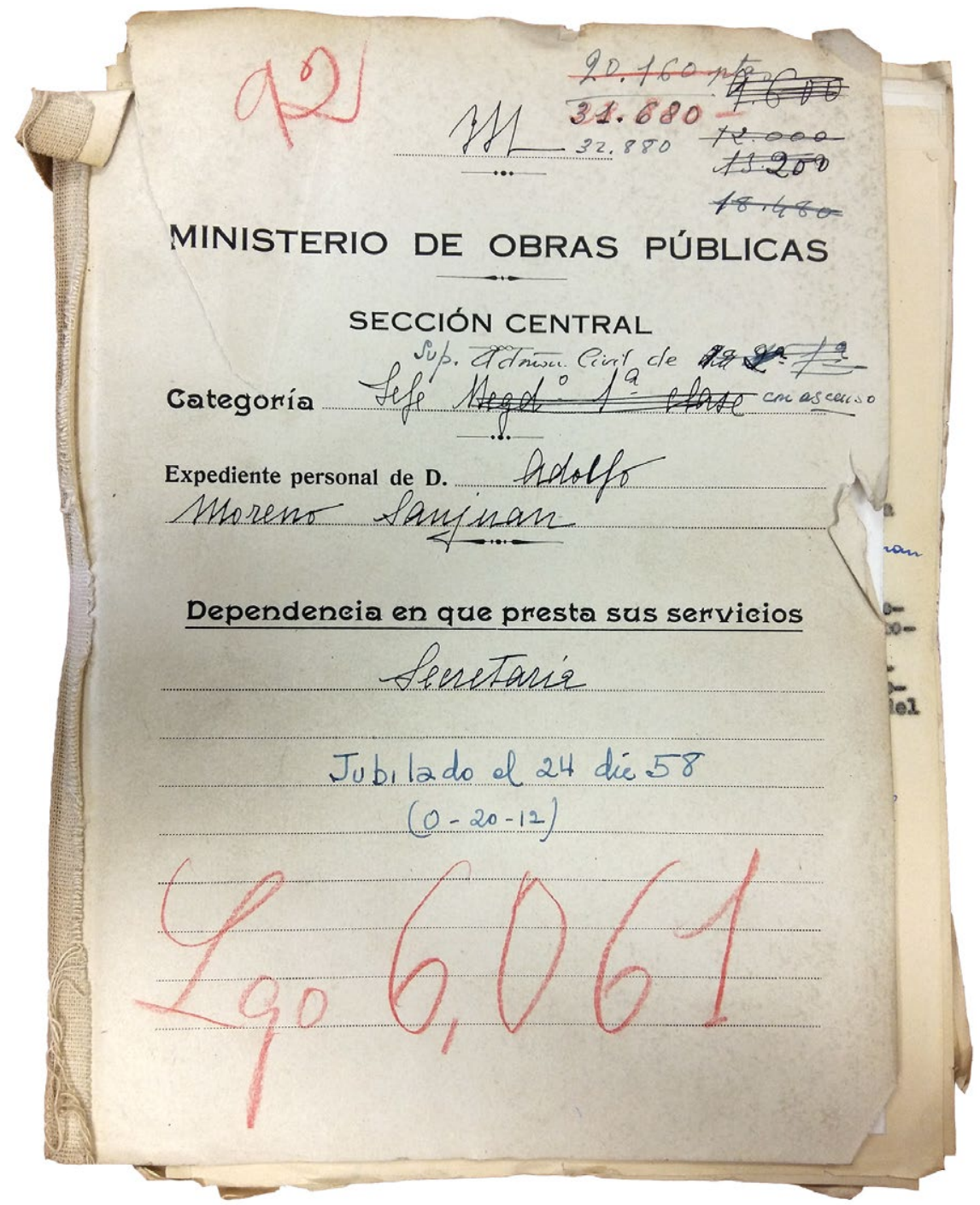

I. Portada del expediente laboral de Adolfo Moreno Sanjuán. Archivo General del Ministerio de Transportes, Movilidad y Agenda Urbana, España, Personal, leg. 606I. 


\section{DOI: https://doi.org/10.22201/iie.18703062e.2021.119.2757}

II4

PABLO ALLEPUZ GARCÍA

exclusivamente por culpa de su escasa destreza técnica y la fuerte exigencia de las pruebas.

Lejos de claudicar ante ese contratiempo, obtuvo el permiso y la ayuda económica de su padre para proseguir con el plan de hacerse pintor en el estudio de José Garnelo y Alda, primera medalla en la Exposición Nacional de Bellas Artes de I892 y catedrático de Dibujo del Antiguo y Ropajes desde I899. Allí encontró un ambiente propicio para preparar el examen, por cuanto implicaba el sometimiento a una disciplina con horarios fijos, y pronto venció su timidez gracias a la solicitud de sus tres compañeros y el talante del maestro.

Don José era bondadoso, delicado en sus maneras y un perfecto caballero, así como también era un gran profesor. [...] a los pocos días, me indicó podía ir también a dibujar a su clase de la citada Escuela, sentándome en sitio que estuviese vacío, y dibujar — de lo que pudiera — lo que más me apeteciese, como así lo hice. Todos los días me corregía en su clase, lo mismo que a los alumnos oficiales. Al poco tiempo parecía no estar descontento de mí, a juzgar por la amabilidad con que me trataba, por el interés que ponía en que me enterase bien de lo que me explicaba y hacerme fácil el trabajo. ${ }^{19}$

Así continuó hasta septiembre de I9ıo: al fin, con tres años de retraso, y aun volviendo a suspender en septiembre y en noviembre, logró ingresar en la Escuela; ${ }^{20}$ acto seguido abandonó el estudio particular de Garnelo, aunque asistiría a sus clases oficiales año tras año. ${ }^{21}$ La experiencia acumulada junto a él le facilitaría la adaptación a ese entorno educativo — con el que ya estaba familiarizado - donde coincidiría con personajes tan diversos como Alejandro Pardiñas, Juan Adsuara o Pedro Muguruza, entre otros. Tanto es así que el curso

19. Moreno Sanjuán, Memorias biográficas, I4-I5.

20. Archivo General de la Universidad Complutense de Madrid (en adelante AGUCM), caja I07/09-IO, cursos I909-I910 y 1910-I9II.

2I. El expediente académico personal de Adolfo Moreno Sanjuán no se ha podido localizar en la caja I5o del Archivo Histórico de la Biblioteca de la Facultad de Bellas Artes de la Universidad Complutense de Madrid (en adelante AнвғваUсм), de manera que la reconstrucción de su paso por la Escuela depende casi en exclusiva de los registros de matrícula de cada curso - estos sí conservados - y de su propio relato autobiográfico — con todas las precauciones posibles-, pues las noticias sobre él por parte de terceras personas son nulas. 


\section{DOI: https://doi.org/10.22201/iie.18703062e.2021.119.2757}

(AUTO)BIOGRAFÍA DE UN FRACASO: EL PINTOR-FUNCIONARIO

I9IO-I9II, nada más incorporarse, dice obtener diploma de primera en todas las asignaturas. ${ }^{22}$

Los dos cursos siguientes estuvieron marcados por las obras de rehabilitación en el edificio principal de la Escuela, de cierta envergadura e incierta duración: la mayoría de las clases se suspendieron indefinidamente, otras se mantuvieron con gran irregularidad, los profesores daban muestra de su incomodidad y apenas unos pocos alumnos terminaron matriculándose. Durante I9II-I9I2 Moreno Sanjuán sólo lo hizo en Dibujo del Antiguo y Ropajes, con Garnelo, y asistía como oyente a Anatomía Artística, por la personalidad cautivadora de José Parada Santín; durante I9I2-1913, añadió la de Paisaje y obtuvo medalla de primera en Dibujo del Antiguo y Ropajes. "Así se pasan los años I2 y I3, por mi parte, casi sin hacer nada". ${ }^{23}$

A pesar del esfuerzo invertido para acceder a la Escuela y de la ilusión puesta en el comienzo de sus estudios, el segundo y el tercer curso se resolvieron con escaso provecho. Ante la posibilidad de malgastar un año más sin demasiado beneficio, se informó sobre las clases particulares de Cecilio Plá - del que tenía buenas referencias por medio de algunos compañeros- y recabó una vez más el respaldo paterno para hacer frente a los elevados costos que ello acarreaba. Al igual que Garnelo, Plá demostró ser un profesor atento a los avances del alumno y durante todo el curso I9I3-I9I4 compaginó dichas lecciones privadas con una considerable carga discente en la Escuela.

Desde los primeros días Don Cecilio parecía corregirme con interés de que me enterase bien de sus lecciones, y al poco tiempo y con frecuencia, empezó a alabar mis trabajos y a decirme que tenía personalidad; recomendándome que no fuera a copiar a ningún Maestro del Museo del Prado, como ya lo había hecho en dos ocasiones, hasta que él me lo dijese. ${ }^{24}$

Para el curso I9I4-I9I5 todo volvió a la normalidad: la Escuela inauguró los nuevos locales, las lecciones retomaron su funcionamiento habitual y Adolfo enca-

22. Hay ciertos desfases entre el relato de Adolfo y la información oficial conservada tanto en el AGUCM, I07/09-02 y I07/09-03 como en el AHBFBAUCM, I99-I, 199-2 y 200. Véase la síntesis de todo ello en la figura 2.

23. Moreno Sanjuán, Memorias biográficas, i7.

24. Moreno Sanjuán, Memorias biográficas, i8. En el Registro de copistas del Museo del Prado de los ańos I906-I9I4 (signatura L35) consta su nombre con fecha de I8 de enero de I9I2 y recomendación del entonces director de la Escuela, Antonio Muñoz Degrain. 


\section{DOI: https://doi.org/10.22201/iie.18703062e.2021.119.2757}

raba su último año con asignaturas de segundo grado; además, abandonó el estudio de Cecilio Plá para ahorrarse ese importante desembolso y dedicarse por entero a las asignaturas restantes. A diferencia de Garnelo, parece que Plá quedó contrariado por ese repentino abandono y se cobraría su venganza como profesor de Estética del Color: a pesar de aquellas cumplidas felicitaciones, a la hora de valorar la última figura —un busto de la gitana Agustina - le otorgó un diploma de segunda que empañaba las calificaciones de ese curso (fig. 2 ). ${ }^{25}$

Este suceso en apariencia intrascendente da la medida del personaje, pues probablemente no fuera tanto una cuestión de frustración académica como de pundonor y orgullo personal, máxime teniendo en cuenta que su currículo general no había sido ni mucho menos excelso. Así que la finalización de los estudios oficiales dejó en él impresiones contradictorias: por una parte, había aprobado todas las asignaturas necesarias para ser pintor, y en ese sentido pudo dar por cumplido su sueño; por otra, le había sentado tan mal la jugarreta de Plá, sin una palabra de consuelo o justificación, que se prometió no volver más por la Escuela. ${ }^{26}$

\section{La confirmación de las sospechas: de pintor a funcionario}

Salir por la puerta de atrás de la Escuela no fue un movimiento inteligente: mientras que otros alumnos — como él mismo indica- solían permanecer varios ańos frecuentando las lecciones que más les interesaban o avivando el contacto con los profesores que más les convenían, Adolfo cometió la torpeza de desvincularse casi por completo de las dinámicas estudiantiles y de perder el favor de dos personalidades de la talla de José Garnelo y Cecilio Plà.

En tales circunstancias, se le presentaba un horizonte no precisamente halagüeño: rondaba ya la treintena, edad más que considerable en la época para un pintor sin experiencia; la economía familiar no era ni mucho menos desahogada, y sus padres presionaban desde la distancia para que optara por una emancipación con garantías; carecía de amparo institucional o personal, consecuencia de sus malas elecciones estratégicas; los réditos de la venta de cuadros se antojaban a todas luces insuficientes, a pesar del relativo interés generado; y aunque de vez en cuando se convocaban plazas de profesor en

25. Moreno Sanjuán, Memorias biográficas, I8-19.

26. Moreno Sanjuán, Memorias biográficas, 18. 


\section{DOI: https://doi.org/10.22201/iie.18703062e.2021.119.2757}

(AUTO)BIOGRAFÍA DE UN FRACASO: EL PINTOR-FUNCIONARIO

\begin{tabular}{|c|c|c|c|c|c|c|c|c|}
\hline & 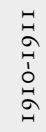 & 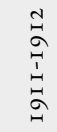 & 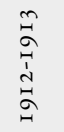 & 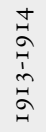 & 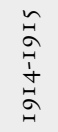 & 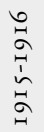 & 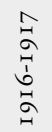 & 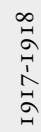 \\
\hline \multirow[t]{2}{*}{ Teoría de las BB.AA. } & & \multirow{8}{*}{ 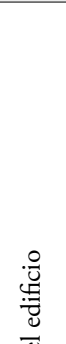 } & & I & $\mathrm{I}$ & & & \\
\hline & & & & & $1^{a}$ & & & \\
\hline \multirow[t]{2}{*}{ Historia de las BB.AA. } & & & & I & I & & & \\
\hline & & & & & $2^{a}$ & & & \\
\hline \multirow[t]{2}{*}{ Perspectiva } & & & & I & $\mathrm{I}$ & & & \\
\hline & & & & & $1^{a}$ & & & \\
\hline \multirow[t]{2}{*}{ Anatomía artístia } & & & & I & I & & & \\
\hline & & & & . & $1^{\mathrm{a}}$ & & & \\
\hline \multirow{2}{*}{$\begin{array}{l}\text { Dibujo del Antiguo y } \\
\text { Ropajes }\end{array}$} & I & \multirow{3}{*}{ 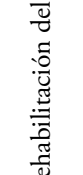 } & $\mathrm{I}$ & I & $\mathrm{X}$ & & & \\
\hline & & & $1^{\mathrm{a}} 1^{\mathrm{a}}$ & $2^{a}$ & & & & \\
\hline Dibujo del natural & & & & & & I & $\mathrm{I} / 8$ & I \\
\hline \multirow[t]{2}{*}{ Paisaje } & & 总 & I & & I & & & \\
\hline & & 离 & & & $1^{a} 1^{a}$ & & & \\
\hline \multirow[t]{2}{*}{ Colorido y composición } & & 0 & & & & $\mathrm{I}$ & $I / 6$ & \\
\hline & & $\frac{n}{\pi}$ & & & & $2^{a}$ & & \\
\hline Teoría estética del color & & $\bar{\pi}$ & & & & I & $\mathrm{I} / 4$ & \\
\hline Pintura decorativa & & $\begin{array}{l}\tilde{J} \\
\tilde{o}\end{array}$ & & & & I & $\mathrm{I} / 7$ & \\
\hline Sin identificar / Ropajes & & 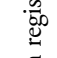 & & & & & 7 & \\
\hline \multirow{2}{*}{ Sin identificar / Estética } & & $\omega$ & & & & & $\mathrm{I} / 8$ & \\
\hline & & & & & & & $2^{a}$ & \\
\hline
\end{tabular}

2. Relación de asignaturas matriculadas y diplomas obtenidos en cada curso. Elaboración propia a partir de los datos del Archivo General de la Universidad Complutense de Madrid y del Archivo Histórico de la Facultad de Bellas Artes de la Universidad Complutense de Madrid (los exclusivos del primero, en azul; del segundo, en rosa; las coincidencias, en verde).

escuelas artísticas o industriales, sus posibilidades de competir en igualdad con otros candidatos por uno de esos puestos se reducían al mínimo. Así pues, ante la incertidumbre del mundo del arte, la seguridad del funcionariado: en 1917 ingresó en la Escala Auxiliar del Cuerpo Técnico-Administrativo del entonces Ministerio de Fomento — más tarde de Obras Públicas—, donde pasó por diversas secciones y departamentos. 


\section{DOI: https://doi.org/10.22201/iie.18703062e.2021.119.2757}

II8

PABLO ALLEPUZ GARCÍA

Su hoja de servicios ${ }^{27}$ resulta bastante caótica durante los años anteriores a la Guerra Civil: escribiente de tercera temporero hasta noviembre de 1918, auxiliar de tercera, segunda y primera clase entre I9I8 y 1922 y oficial de administración de tercera y de administración civil hasta la II República; durante ese tiempo acumuló una buena cantidad de licencias por asuntos personales o bajas por enfermedad que iba encadenando unas tras otras y que le costó algún apercibimiento por su conducta. A partir de la posguerra, gracias a la exención de depuración laboral, ${ }^{28}$ su situación se estabilizó e inició una serie de ascensos constantes: durante la década de los ańos cuarenta, como jefe de Negociado de tercera, segunda y primera clase; durante la década de los años cincuenta, como jefe de Administración de tercera, segunda y primera clase; hasta que, en 1958, ya con el cargo de jefe superior del Cuerpo de Administración Civil, cumplió la edad reglamentaria de 70 años y se jubiló definitivamente.

Sin embargo, la despreocupación de percibir un sueldo fijo cada mes y de poder vivir sin apuros en Madrid contrastaba con la desazón que le producía la renuncia a sus aspiraciones artísticas. En sus memorias cuenta amargamente la nefasta incidencia de este empleo sobre su rutina pictórica, ya que después de pasar toda la mañana trabajando a disgusto encerrado, apenas le quedaba motivación para coger los pinceles por la tarde, y en cambio necesitaba salir a tomar el sol y ver a las chicas; es decir, se vuelve más remolón para trabajar en la pintura y sólo lo hace cuando tiene algún retrato de encargo o siente "impulsos incontenibles", así que pasa de profesional a aficionado. ${ }^{29}$

Esa pérdida de categoría la cifra él sobre todo en el hecho de no contar con un estudio independiente y bien equipado, factor diferencial para mantener el respeto de sus colegas y la confianza de una hipotética clientela. La mixtificación del estudio del pintor arrastra un importante componente romántico, ${ }^{30}$ pero también responde a cierto pragmatismo: su apuesta estética, basada en la mímesis de la pintura académica tradicional, requiere una especial atención al

27. El expediente laboral completo de Adolfo Moreno Sanjuán puede consultarse en AGMITMA, leg. 606I.

28. agmitm, leg. 606I, "Minuta del 2 de enero de 1940" y "Carta de D. Ángel Michelena y Villanueva", 27 de agosto de 194I. La misma carta se encuentra en el Archivo General de la Administración (en adelante AGA), (5)I.7, caja 31/07428, Boletín, núm. I68.

29. Moreno Sanjuán, Memorias biográficas, 22-23. Véase Carlos Eymar, El funcionario poeta. Elementos para una estética de la burocracia (Madrid: Fórcola, 2009).

30. Esperanza Guillén, Retratos del genio (Madrid: Cátedra, 2007) y Calvo Serraller, La novela del artista, 67-70. 


\section{DOI: https://doi.org/10.22201/iie.18703062e.2021.119.2757}

(AUTO)BIOGRAFÍA DE UN FRACASO: EL PINTOR-FUNCIONARIO

ambiente representado, la luz, el modelo, la pose, el vestuario, necesidades que el espacio doméstico no puede satisfacer en absoluto; como tampoco ofrece la posibilidad de trabajar grandes formatos ni de plantear composiciones ambiciosas, por lo que debe olvidarse de obtener ningún tipo de recompensa en certámenes.

\section{Por amor al arte: ¿qué hace un funcionario como tú en una exposición como ésta?}

La vía para no perder el contacto con la esfera artística iba a ser la Asociación de Pintores y Escultores, fundada en I9IO y organizadora, a partir de 1920, de los célebres Salones de Otoño. Con toda probabilidad, Adolfo estaba ya al tanto de la actividad de la Asociación, pues sin ir más lejos Garnelo había sido socio fundador y responsable de su revista Por el Arte, pero no se haría miembro hasta un momento indeterminado entre ambas fechas; ${ }^{31}$ ello sería el comienzo de una larga y fluctuante relación, no exenta de tiranteces, durante unos 40 años. ${ }^{32}$

Las primeras participaciones en dichos Salones resultaron muy satisfactorias para él, no sólo porque le admitieran los cuadros sino también por sus colocaciones, lejos de las declaradamente malas y cada vez más cerca de las buenas: ${ }^{33}$ en el segundo, de I92I, un óleo titulado Sirve a la patria aunque fallezca tu padre; ése es tu deber; ${ }^{34}$ en el tercero, de 1922, otros dos, Una verata

3I. Hay constancia de pagos de cuotas al menos desde la séptima a la undécima, incluidas. Veáse, respectivamente, Gaceta de Bellas Artes. Revista Quincenal Ilustrada, Órgano de la Asociación de Pintores y Escultores, núm. 166 (I5 de abril de I92I): I3; núm. I68 (I5 de mayo de I92I): I5 y núm. I83 (I de enero de I922), suplemento; núm. I98 (I5 de agosto de I922): IO-II; núm. 200 (I5 de septiembre de 1922): 7 y núm. 202 (I5 de octubre de I922): II; núm. 23I (I de enero de 1924): I4.

32. Los registros conservados por la propia Asociación son incompletos y confusos, por lo que deben tomarse con precaución: Adolfo Moreno Sanjuán figura en el periodo de I9Io a 1950 con especialidad de pintura y fecha de nacimiento/alta de 1936 —en cualquier caso, incorrecta—, así como en el periodo de 1950 a 1993 con especialidad de dibujo — lo cual no sería tampoco del todo preciso - sin más datos. Véase Fernando de Marta Sebastián, Historia de la Asociación Española de Pintores y Escultores I9I0-1993. Ocho décadas de Arte en España (Madrid: Asociación Española de Pintores y Escultores, 1994), 604, 636 y 669.

33. Moreno Sanjuán, Memorias biográficas, 2I.

34. Catálogo del Segundo Salón de Otoño (Madrid: Asociación de Pintores y Escultores, 192I), 21. Véase Gaceta de Bellas Artes, núm. 176, I5 de septiembre de 1921, I5. 


\section{DOI: https://doi.org/10.22201/iie.18703062e.2021.119.2757}

$\mathrm{I} 2 \mathrm{O}$

PABLO ALLEPUZ GARCÍA

(Cáceres) y Mi amigo, además de un dibujo al lápiz, Retrato de la Sra. González Álvarez, ${ }^{35}$ delante de los cuales al parecer se detuvo Garnelo para mirarlos con detenimiento y ponderarlos; en el cuarto, de I923, dos pinturas más, Inocencia y Un panó con tres paisajes; ${ }^{36}$ en el quinto, de 1924, de nuevo otras dos, La vuelta de la ronda (tipos de la Vera, Cáceres) y Esperanza. ${ }^{37}$

Esta proyección ascendente se vio truncada, según él, por la renovación de la Junta Directiva, a la que habían accedido algunos de sus condiscípulos, y pronto comenzaría el declive de su posición: "yo sufro todo esto resignadamente, sin quejarme a nadie y como no solamente no me quejo, sino que estoy como siempre, amable, correcto y deferente", aquéllos "se creen que soy tonto o un pobre hombre al que se le pueden hacer todas las perrerías que se quieran" ${ }^{38}$ La gota que colmó el vaso de su paciencia llegaría al tercer año consecutivo de tales agravios, cuando además explicitaron mediante la revista de la Asociación que en la sala donde se encontraban sus obras habían hacinado todo lo malo por no rechazarlo. ${ }^{39} \mathrm{Al}$ día siguiente de enterarse, todavía con el ímpetu del enfado, escribió al presidente para darse de baja "por no querer deslucir el Salón de Otońo con mis obras. No volví a mandar nada"..$^{\circ}$

Algo antes, en pleno apogeo de sus participaciones en los Salones, se había animado a presentar obra por primera vez a la Exposición Nacional de Bellas Artes de 1924, pero su óleo Vestigios fue rechazado por un jurado presidido por Cecilio Plá; ${ }^{41}$ como también lo fueron en 1930 Cerrando el trato y Desde mi balcón, ${ }^{42}$ en 1932 Ruinas y Alisos, ${ }^{43}$ en 1934 Plaza de Bohoyo (Gredos) y Sierra de

35. Catálogo del Tercer Salón de Otoño (Madrid: Asociación de Pintores y Escultores, 1922), 23.

36. Catálogo del Cuarto Salón de Otoño (Madrid: Asociación de Pintores y Escultores, 1923), 22.

37. Catálogo del Quinto Salón de Otoño (Madrid: Asociación de Pintores y Escultores, 1924), 22.

38. Moreno Sanjuán, Memorias biográficas, 2I-22.

39. No se han podido identificar ni el artículo concreto ni el Salón en cuestión, aunque todo apunta hacia 1924; a pesar de ello, debe entenderse la reacción en línea con los enconados debates sobre el espíritu de las convocatorias o la calidad de las propuestas que se reproducían en los números 201 y 202, de 1922, o 226 y 227, de 1923.

40. Moreno Sanjuán, Memorias biográficas, 22.

4I. AGA, (5)I.7, caja 3I/07407, "Libro de resguardos", núms. 4OI-600, resguardo núm. 5I4; AGA, (5)I.7, caja 3I/07409, Listas de expositores, "Señores expositores de la sección de pintura", 6; "Relación de los señores expositores por orden riguroso de presentación de obras", I7; AGA (5)I.7, caja 31/07408, leg. 21943, "Libro de boletines de obras rechazadas", núm. 913.

42. AGA, (5)I.7, caja 3I/074I3, resguardo núm. 24; AGA (5)I.7, caja 31/074I5, Boletín de Inscripción, s. n.; AGA, (5)I.3, caja 3I/oIO30, "Acta del jurado de admisión y colocación".

43. AGA, (5)I.7, caja 3I/074I6, "Libro de resguardos", núms. 20I-400, resguardo 206. 
Bohoyo ${ }^{44}$ y en 1936 iiiMuchos ya!!! y Retrato de la Sra. de M., ${ }^{45}$ según él "no por peores, sino por lo que fuera”. ${ }^{46}$ Durante todos esos años sólo le aceptaron un lienzo, Cacharros, en 1932, que además consideraba bien colocado; ${ }^{47}$ opinión no compartida por la prensa, pues hacía notar que en la sala XIV, "bastante floja en general", decaía el interés por su "conjunto de medianías y vulgaridades", entre las que Cacharros se enumera dentro de las "más inferiores categorías". ${ }^{8}$ El balance resulta ciertamente pobre y el desencanto era compartido por algunos de sus amigos, quienes le aclararon que las Nacionales se mueven por favoritismo, aunque él se empeñara en declinar la oferta que le hacía un señor político: "recomendado, siempre tendría la duda si no habría sido admitido solamente por la recomendación. Prefiero, si ha de ser así, no volver a presentar". ${ }^{49}$

Cada vez más íntegro, cada vez menos integrado, por esa época le surgió una gran oportunidad para explotar sus intereses gracias a lo que él denomina "Exposición del Traje Regional" de manera un tanto confusa. Sobre la base del consenso obtenido por la Exposición del Traje Regional e Histórico de 1925, punto de partida para la percepción social de un patrimonio invisibilizado hasta el momento, el Concurso Nacional de Pintura de 1934 había abierto la recepción de obras de tamaño natural que sirvieran de complemento documental para los fondos del Museo del Pueblo Español; ;o "un tema español, para pintores genuinamente españoles" ${ }^{\text {I }}$ — valga la redundancia — que apro-

44. AGA, (5)I.7, caja 3I/O742I, Boletín de Inscripción, núm. 257; "Libro de resguardos", resguardo núm. 80; AGA, (5)I.7, caja 31/07422, "Lista de señores expositores en la sección de pintura”, núm. 58 .

45. AGA, (5)I.7, caja 31/07424, leg. 21952, segunda parte, Boletín de Inscripción, núm. I73; AGA, (5)I.7, caja 3I/07425, "Libro de resguardos de obras retiradas", resguardo núm. 248; AGA, (5)I.7, caja 31/07418, Boletín de Inscripción s.n.

46. Moreno Sanjuán, Memorias biográficas, 3I.

47. AGA, (5)I.3, caja 3I/oro3I, "Actas de actuación del Jurado de admisión y colocación de obras", Boletín, núm. 206; Catálogo oficial de la Exposición Nacional de Bellas Artes de 1932 (Madrid: Blass S.A., 1932), 30.

48. El Noticiero Gaditano. Diario de información y de intervención política, núm. 5045, io de junio de $1932,3$.

49. Moreno Sanjuán, Memorias biográficas, 27.

50. Gaceta de Madrid, núm. I27, 7 de mayo de 1934, 900. Véase María Antonia Herradón Figueroa, "Icono y Patrimonio. El traje popular en la Edad de Plata", en La palabra vestida II. Indumentaria histórica y popular (Soria: Diputación Provincial de Soria, 2016), 67-95.

5I. Luis de Galinsoga, "El concurso nacional de pintura de este año. Un tema español, para pintores genuinamente españoles", $A B C, 4$ de diciembre de 1934, 6-7. 


\section{DOI: https://doi.org/10.22201/iie.18703062e.2021.119.2757}

PABLO ALLEPUZ GARCÍA

vechó para colocar entre el más de medio centenar de propuestas su Tipos de Bohoyo (Ávila), sin recibir ninguna mención. ${ }^{52}$

\section{Un punto de inflexión omitido: la Escuela de Veterinaria por la Guerra Civil}

A pesar de los innumerables obstáculos y el callejón sin salida al que se había abocado él mismo, llegados los ańos treinta Adolfo parece haber alcanzado una doble madurez — teórica y práctica - como artista. Teórica, porque para entonces había forjado una postura muy clara acerca de su panorama inmediato: "por esta época empieza a manifestarse en la pintura, el vanguardismo, el cubismo y demás 'ismos', como igualmente el abstracto", aunque "la mayoría de la gente lo toma a broma y muchos se indignan ante los cuadros de estos estilos; más que nada, porque se les va dando una importancia oficial que no tienen"; una situación que él achaca a la connivencia de ciertos críticos, deseosos de llevar la contraria a la opinión general y de imponer su superioridad intelectual, que terminan por confundir a los aprendices de artista. ${ }^{53} \mathrm{Y}$ práctica, porque estaba convencido de haber avanzado aun pintando a trompicones: "mi paleta se va modificando; va adquiriendo luminosidad, limpieza de color, justeza de tonos", hasta el punto de que "las lecciones de Don Cecilio, muy buenas para enseńar, las voy olvidando y pinto a mi modo, que creo me da buenos resultados"; ${ }^{4}$ lo cual implica en cierto modo resarcirse de la afrenta casi 20 años después, por cuanto ha conseguido dejar atrás al maestro y ha encontrado su propio lenguaje plástico. 5

52. Moreno Sanjuán, Memorias biográficas, 30. Para el listado de participantes, véase el artículo anónimo "El 'barnizado' de las obras del Concurso Nacional de Pintura", $A B C, 23$ de noviembre de $1934,43-44$.

53. Moreno Sanjuán, Memorias biográficas, 29-30. En este extremo coincide por ejemplo con las opiniones vertidas por Gil Fillol en su sección "Pasado y futuro del arte" de la Gaceta de Bellas Artes: véase "Responso al "vanguardismo", núm. 459, primer trimestre de 1944, s. p.; “Cuadros sin 'asunto”, núm. 460, segundo trimestre de 1944, s. p.; o "Responsabilidad de la crítica”, núm. 46I, 1945, s. p.

54. Moreno Sanjuán, Memorias biográficas, 27.

55. La superación del maestro y la adquisición de un estilo único acorde a la propia personalidad constituye uno de los temas más fecundos desde la Antigüedad clásica —véase Kris y Kurz, La leyenda del artista, 3I-62-, consolidado por la incipiente disciplina de la Historia del Arte y que en consecuencia ha permeado en las mentalidades de numerosas generaciones de artistas, como así lo evidencian sus relatos autobiográficos: por no abandonar 
Esta confianza la corrobora un acontecimiento insólito en su carrera, que marca la transición entre las décadas de los años treinta y cuarenta: durante el gobierno de la II República, en I93I, el Claustro de Profesores de la Escuela de Veterinaria de Madrid le solicitó un cuadro alegórico para su salón de actos, no muy bien pagado pero en todo caso ajustado a su caché.$^{56} \mathrm{La}$ figura semidesnuda que preside la composición, "preciosa, original, llena de movimiento y gracejo", distinta para él a otras coetáneas carentes de movimiento, le satisfacía por completo, la enseñó a multitud de compañeros del Ministerio e incluso le procuró algunos encargos posteriores. Pero, por desgracia, el mismo Claustro se deshizo de él por miedo justo antes de que entraran las tropas del General Franco en Madrid: "esta destrucción me ha causado gran pena, pero no tiene remedio y hay que olvidarlo". 57

El relato que Moreno Sanjuán proporciona de la Guerra Civil tiene que ver tan sólo con este suceso anecdótico: tanto esfuerzo hace por olvidar esa pérdida que termina por no mencionar en sus memorias otros hechos bastante más notables. Primero, que cuando tuvo conocimiento del alzamiento militar se presentó en prueba de adhesión en la Jefatura de Obras Públicas de Segovia, donde se encontraba entonces y donde desempeñó desde un principio su destino $;{ }^{58}$ nada más terminar el conflicto inició las gestiones para volver a Madrid y logró la reincorporación en agosto de 1939. 59 Segundo, que apenas unos meses más tarde, en noviembre, la dirección de la Escuela Superior de Veterinaria lo nombró con carácter provisional para la plaza vacante de fotógrafo y pintor, con una gratificación anual de I,500 pesetas, y enseguida tomó posesión de su cargo; ${ }^{60}$ quién sabe si como compensación por aquella destrucción

el ámbito español, Salvador Dalí, "La vida secreta de Salvador Dalî", en su Obra completa, vol. I. Textos autobiográficos I (Barcelona: Destino, 2003), 489-492; Fernando Álvarez de Sotomayor, "Recuerdos de un viejo pintor", en Memorias de Fernando Álvarez de Sotomayor. Fomento y apreciación de las artes, eds. Pedro Zamorano Pérez, Rodrigo Gutiérrez Viñuales y Juan Manuel Monterroso Montero (Santiago de Compostela: Servicio de Publicaciones e Intercambio Científico de la Universidad de Santiago de Compostela, 2016), 38-39.

56. En los libros de actas de las sesiones del Claustro de Profesores de la Escuela de Veterinaria (AGUCM, caja 53/06-002) no aparece mención a dicho encargo.

57. Moreno Sanjuán, Memorias biográficas, 28-29.

58. AGA, (5)I.7, caja 3I/O7428, Boletín, núm. I68, "Carta de D. Ángel Michelena y Villanueva”, 27 de agosto de I94I.

59. agmitma, leg. 606I, "Comunicación del 3 de abril de I939"; "Minuta del 2I de abril de I939"; "Orden del 4 de agosto de I939".

6o. AGUCM, caja V/O2-033, "Expediente personal de D. Adolfo Moreno Sanjuán”; AGA, 


\section{DOI: https://doi.org/10.22201/iie.18703062e.2021.119.2757}

reciente o simplemente por una más que posible intervención de su cuñado Rafael González Álvarez, a la sazón catedrático y director de la Escuela a lo largo de esa década. ${ }^{61} Y$ tercero, pero no menos importante, que todas esas decisiones le facilitarían bastante el porvenir a partir de entonces.

\section{Arte de posguerra: nuevas posibilidades \\ en un contexto por reconstruir}

El panorama artístico en España había cambiado sustancialmente después de la Guerra Civil;,62 en principio, de manera favorable a los intereses de un Adolfo Moreno Sanjuán, por cuanto se impuso una concepción de la pintura, la temática y el estilo más próxima a su credo estético. Quizá ello explique su segunda y última admisión a una Nacional, la de 1941, según Bernardino de Pantorba una de las ediciones más pobres en número y calidad de las celebradas durante lo que iba del siglo:63 su obra Madrinas de guerra, descrita como "chicas leyendo las cartas de sus ahijados", se expuso en la sala XVII y atrajo algunas miradas, ${ }^{64}$ entre ellas la del crítico Cecilio Barberán. ${ }^{65}$

(05)000, caja 2I/2039I, "Expedientes de personal que ha cesado", I5073-86.

6I. Véase Miguel Cordero del Campillo, "Rafael González Álvarez", en Miguel Cordero del Campillo, Carlos Ruiz Martínez y Benito Madariaga de la Campa, dirs., Semblanzas Veterinarias. Volumen II (Madrid: Consejo General de Colegios Veterinarios, 1978), 27I-279.

62. Véase María Dolores Jiménez-Blanco, comp., Campo cerrado. Arte y poder en la posguerra española. 1939-1953 (Madrid: Museo Reina Sofía, 2016).

63. Bernardino de Pantorba, Historia y critica de las Exposiciones Nacionales de Bellas Artes celebradas en España (Madrid: Jesús Ramón García-Rama, 1980), 306. Ni siquiera en esa circunstancia cita a Moreno Sanjuán en su larga retahíla de participantes, como tampoco lo había hecho en la de 1932. Véase también Lola Caparrós Masegosa, Instituciones artísticas del franquismo. Las exposiciones nacionales de Bellas Artes (I94I-I968) (Zaragoza: Prensas de la Universidad de Zaragoza, 2019).

64. AGA, (5)I.7, caja 3I/07428, Boletín de inscripción, núm. I68; AGA, (5)I.7, caja 3I/07407, resguardo núm. 230; en el resguardo equivocan su nombre por el de Alfonso [sic.] Moreno Sanjuán, Catálogo oficial de la Exposición Nacional de Bellas Artes de 194I (Madrid: Ministerio de Educación Nacional, 194I), 42 y 85. Véase Ángel Llorente Hernández, "Vencidos y enemigos en la pintura y la ilustración franquistas de la primera postguerra”, en Retóricas del miedo. Imágenes de la guerra civil española, eds. Nancy Berthier y Vicente Sánchez-Biosca (Madrid: Casa de Velázquez, 2012), 196.

65. Cecilio Barberán, "La Exposición Nacional de Bellas Artes. Examen de obras", $A B C, 28$ de noviembre de 194I, I5; Moreno Sanjuán, Memorias biográficas, 32. 
Pero también en la misma le rechazaron un Autorretrato y en 1943 dos naturalezas muertas, Evocación y Brillos y reflejos, ${ }^{66}$ lo cual generó en él una profunda desmotivación: "como estoy convencido de que mis cuadros no están para ser rechazados y de que hacen buen papel, aun entre los de los pintores ya consagrados" — afirma tajante- "y además soy refractario al palustre, a la recomendación, ni me gusta pedir favores, prometo no volver a ninguna Nacional, como así lo he cumplido"; y no contento con ello, añade que a partir de entonces "estas Exposiciones Nacionales se irán llenando de cuadros de pintura infantil o de dementes que colgarán en los mejores sitios y obtendrán las mejores recompensas" ${ }^{67}$ Desde su punto de vista, sin duda ampliamente compartido, la vanguardia no sólo es deshonesta sino también patológica.

Ante el temor de quedar aislado por completo, volvió a mostrar interés en los círculos artísticos por enésima vez en su carrera. Después de cierta insistencia, aceptó la invitación de su vendedor de marcos y comenzó a frecuentar una peña de pintores, pero pronto se dio cuenta de que éstos sólo perseguían posibles prebendas por parte del dueño y de que entre ellos se halagaban tanto en presencia como se denostaban en ausencia; "en la mayoría de los pintores anida en sus corazones la egolatría y fuera de ellos no puede haber nadie mejor", de lo cual "no se salva nadie: ni el que verdaderamente vale, ni el que no vale nada ni puede hacer nada que les perjudique", y así "por todo esto que no encaja en mi manera de ser y obrar, pronto me dejo aquel ambiente nauseabundo en el que no puedo respirar". ${ }^{68}$

En 1940, después de tres largos lustros desvinculado de la Asociación de Pintores y Escultores, había recibido una circular en la que se anunciaba la recomposición total de su Junta Directiva y sus renovados propósitos. Pese al desconocimiento de estos artistas y el recelo ante la propuesta, la intercesión de su mujer determinó un cambio de actitud y accedió a reintegrarse. ${ }^{69} \mathrm{La}$ pertenencia a la Asociación le permitiría más adelante participar con otros

66. AGA, (5)I.7, caja 3I/07430, Boletín, núm. 250; AGA, (5)I.7, caja 3I/07426, "Acta del Jurado de Admisión y Colocación”, puntos $6^{\circ}$ y $7^{\circ}$; en el punto $6^{\circ}$ se refieren de nuevo al artista como Alfonso [sic.] Moreno Sanjuán.

67. Moreno Sanjuán, Memorias biográficas, 32.

68. Moreno Sanjuán, Memorias biográficas, 33-34.

69. Aparte de esta mención, Adolfo excluye del relato a su primera esposa Obdulia González Álvarez, hija y hermana de catedráticos de Veterinaria; véase "Notas sueltas. Bodas", Boletín Profesional de la Revista de Veterinaria, núm. 6, 30 de mayo de 1926, 8. Tampoco menciona a María de las Candelas Durán Almeida, con quien al parecer casó en segundas nupcias. 


\section{DOI: https://doi.org/10.22201/iie.18703062e.2021.119.2757}

I26

PABLO ALLEPUZ GARCÍA

miembros en algunas exposiciones colectivas, por ejemplo el Salón de Primavera celebrado en Palma de Mallorca en $1945,{ }^{70}$ una de bodegones en la Galería Pereantón en enero de $1949^{71}$ o la del cuadragésimo aniversario en el Salón Dardo, ${ }^{72}$ así como retomar la rutina de los Salones de Otoño una vez desestimada la opción de las Nacionales: en 1943 presentó dos óleos con el título Brillos y reflejos ${ }^{73}$ en 1944, otros dos, La espera y Añoranza del domingo (fig. 3);74 en 1945-1946, Meditación $;^{75}$ en 1950, Sinfonía de gamas frías y María Dolores: ${ }^{76}$ en 1952 , Retrato (fig. 4) y Jarro con cardos $;{ }^{77}$ y en 1954 , Recreación. ${ }^{78}$ Aunque ya había asumido ser "incapaz de alcanzar un relieve notable en el Arte", las buenas colocaciones y reseñas le alentaban para seguir alcanzando a los buenos pintores y hasta avivaban la envidia de éstos, que se acercaban para tantear su capacidad de influencia; pero "como no intrigo, ni me quejo, ni exijo, ni molesto ni alboroto, de mí nadie se acuerda ni se preocupa. ¡Qué vamos a hacerle! No puedo ser de otra manera" — se lamenta Adolfo, resignado"aunque sí me apena la poca consideración y el poco afecto que a mi persona se le tiene, después de todo". ${ }^{79}$

Sin embargo, lo más interesante ocurriría a raíz de la edición de 1946, justo una de las pocas en las que no llegó a colgar obra. Adolfo había enviado tres cuadros y sin que sirviera de precedente se decidió a acudir junto a su paisano y

70. Catálogo del Salón de Primavera. Asociación de Pintores y Escultores de España (Palma de Mallorca: s.e, 1945), s.p. Véase, "Exposición en Mallorca", Gaceta de Bellas Artes, núm. 46I, I945, s.p.

71. José Prados López, "Exposición de bodegones de la Asociación de Pintores y Escultores", en su Arte español. Críticas radiadas en la emisora Radio España de Madrid. Tomo II (años 19491950) (Madrid: s.e, 195I), I6-I7.

72. José Prados López, "Exposiciones de la semana”, en Arte español. Críticas radiadas en la emisora Radio España de Madrid, Tomo II, I87-190.

73. Catálogo del XVII Salón de Otoño (Madrid: Asociación de Pintores y Escultores, 1943), 30 y 45 .

74. Catálogo del XVIII Salón de Otoño (Madrid: Asociación de Pintores y Escultores, 1944), 37 y s.p.

75. Catálogo del XIX Salón de Otoño (Madrid: Asociación de Pintores y Escultores, 19451946), 22.

76. Catálogo del XXIV Salón de Otoño (Madrid: Asociación de Pintores y Escultores, 1950), $56-57$.

77. XXV Salón de Otoño. Catálogo informativo de las Secciones de Pintura, Escultura, Grabado, Dibujo y Arte Decorativo (Madrid: Asociación de Pintores y Escultores, 1952), 26 y 65.

78. Catálogo del XXVI Salón de Otoño (Madrid: Asociación de Pintores y Escultores, 1954), 42. 79. Moreno Sanjuán, Memorias biográficas, 31, 34, 47-48. 


\section{DOI: https://doi.org/10.22201/iie.18703062e.2021.119.2757}

(AUTO)BIOGRAFÍA DE UN FRACASO: EL PINTOR-FUNCIONARIO

3. Adolfo Moreno Sanjuán, Añoranza del domingo, XVIII Salón de Otońo (Sala XVI, núm. 170), 1944. Reproducción del catálogo, original en paradero desconocido.

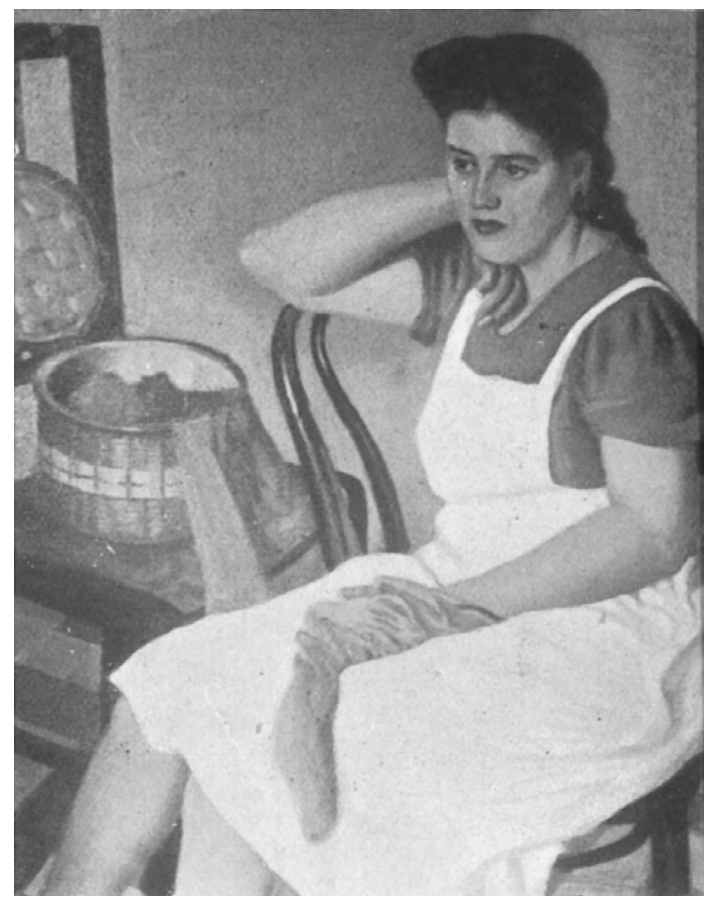

amigo Jacinto Higueras a la apertura oficial, esta ocasión no en el Retiro sino en el más reducido Palacio de Bibliotecas y Museos. Allí pudo comprobar por primera vez en persona la falta de escrúpulos de sus colegas de profesión, todos afanados detrás del Director General de Bellas Artes —el marqués de Lozoya—, el presidente de la Asociación —Eduardo Chicharro- y su secretario — José Prados López- en severa pugna por llamar la atención de las autoridades: "resulta humorista, grotesca y graciosa esta comitiva: los unos, con su aire prestado de conquistadores, de sabios, de puedelotodo; y los otros, de marionetas, deshaciéndose en servilismos y zalemas" ${ }^{80}$ Mientras tanto, Adolfo y Jacinto, aparte del grupo principal, recorrían las salas con la creciente sorpresa e indignación de no encontrar ninguno de sus tres cuadros y saberse en fin excluido.

$\mathrm{Al}$ despedirse de Jacinto y llegar a casa, escribió una carta "dura, terminante, concreta, clara y concisa" ${ }^{\text {" a }}$ a Chicharro, dándose de baja y remitiéndole su

8o. Moreno Sanjuán, Memorias biográficas, 37 .

8I. Moreno Sanjuán, Memorias biográficas, 38. (La carta no ha podido ser localizada). 


\section{DOI: https://doi.org/10.22201/iie.18703062e.2021.119.2757}

carnet de socio, pero la respuesta inmediata y conciliadora de Prados López le hizo recapacitar. Esa breve correspondencia entre ambos significaría el comienzo de una relación cordial, con altibajos, a medida que la distancia marcada por Adolfo fue desapareciendo: si en principio lo invitó a una reunión informal con la promesa de no tocar temas relativos al arte, poco a poco las conversaciones fueron virando hacia su campo de interés común, algún día acaso le manifestara sus intenciones de preparar una exposición con sus cuadros... hasta que en el verano de 1949 el propio Prados López le propuso reservarle el local de la Galería Pereantón — de la que era Director Artístico- para la primera quincena de diciembre. ${ }^{82}$

A pesar de lo mucho que presumía Moreno Sanjuán de mantenerse siempre al margen de los círculos de poder y las intrigas artísticas, este desliz conculca su denodada pulcritud: bien es cierto que no entró en el juego cortesano y ni siquiera solía participar en los almuerzos mensuales organizados por la Asociación, ${ }^{83}$ pero no es menos cierto que su nombre puede encontrarse sin ir más lejos en la relación de entidades y artistas que contribuyeron a la edición del libro homenaje a Prados López justo por esas mismas fechas; ${ }^{84}$ o que a partir de entonces recibió por parte del crítico calificaciones de "meticuloso y concreto en sus afirmaciones, reflexionadas de antemano y realizadas en sus finales con seguridad y honradez", "honradez desusada [...] interés desusado también" o "meticuloso en el matiz colorista y apretado de dibujo, en avance agradable siempre" ${ }^{85}$ En este sentido, fuera por un aprecio personal sincero o por una estrategia premeditada, el desenlace constata su impresión de que buena parte de la escena artística de la época dependía de los contactos.

Una exposición de is días en la galería Pereantón puede parecer un logro insignificante para cualquier artista que integra la historia del arte con mayúsculas, como también pueden ser un mero trámite las Nacionales o un demérito los Salones, pero para Adolfo suponía la única individual en toda su trayectoria y en consecuencia le dedica un capítulo específico en sus memorias. ${ }^{86}$ Hay que recor-

82. Moreno Sanjuán, Memorias biográficas, 4I.

83. Gaceta de Bellas Artes, núm. I70, I5 de junio de I92I, I2.

84. José Prados López, Arte español. Críticas radiadas en la emisora Radio España de Madrid. Tomo I (años 1946-1948) (Madrid: s.e., 1950), 306.

85. José Prados López, "La figura en el XXIV Salón de Otoño", en su Arte español. Críticas radiadas en la emisora Radio España de Madrid. Tomo III (años 1950-1952) (Madrid: s.e., I953), 30; "Exposiciones de la semana”, en su Tomo II, I89; "XXV Salón de Otoño", en su Tomo III, 286. 86. Moreno Sanjuán, Memorias biográficas, 42-47. 


\section{DOI: https://doi.org/10.22201/iie.18703062e.2021.119.2757}

(AUTO)BIOGRAFÍA DE UN FRACASO: EL PINTOR-FUNCIONARIO

4. Adolfo Moreno Sanjuán, Retrato, XXV Salón de Otoño

(Sala II, núm. 39), 1952.

Reproducción del catálogo, original en paradero desconocido.

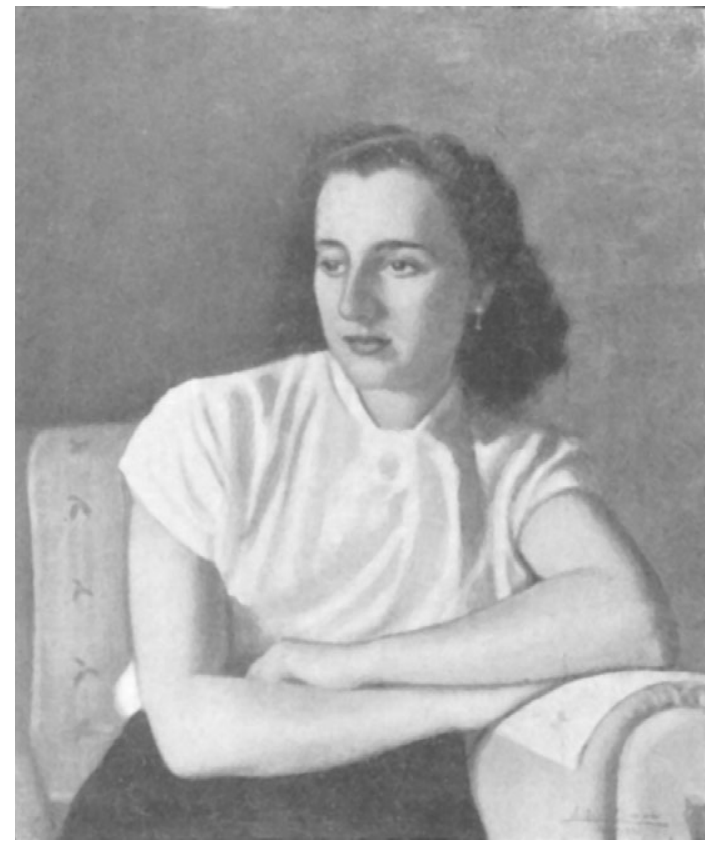

dar en cualquier caso que seguía siendo un completo desconocido tanto para el público general como para el especializado: la información que publicó $A B C$ a propósito de la inauguración en la galería de la calle Hortaleza confundía su nombre por el de Alfonso, ${ }^{87}$ como ya le ocurriera en el recibo de la Nacional de I94I o en el acta del Jurado de admisión y colocación de la de I943, y del mismo modo su paisano Rafael Láinez Alcalá afirmaba en unas notas manuscritas que "hacía muchos años que Moreno Sanjuán, solicitado por otras actividades, apenas acudía a las exposiciones. Muchos ignorábamos su nombre artístico" ${ }^{88}$

La reunión de esos 30 óleos — I8 de figura y el resto bodegones, flores y frutas- (fig. 5) no cosechó ningún éxito, como podría haberse previsto, según

87. $A B C$, I de diciembre de 1949, I4.

88. El documento — del que he corregido las erratas — se conserva en el archivo Rafael Láinez Alcalá del Instituto de Estudios Giennenses (RLA-D-3I-I-38). Tal vez estas notas de Láinez vengan motivadas por alguna conversación con Antonio Nogales, pues allí mismo hay constancia de que mantenían correspondencia por esas fechas (RLA-D-II-2-I8, "Carta de Rafael Láinez Alcalá”, 2 de enero de 1950). 


\section{DOI: https://doi.org/10.22201/iie.18703062e.2021.119.2757}

I3O

PABLO ALLEPUZ GARCÍA

Adolfo a causa de la nómina de malos artistas de la galería y la dejadez de su director, a lo cual sin duda debe ańadirse el escaso carisma del expositor: unos I5 o 20 visitantes al día, expresiones de elogio en algunos catálogos de mano, periodistas que pretendían sacarle los cuartos por un trato de favor, una lección de pintura que le dio un sacerdote delante de sus cuadros, pocos interesados que regateaban en vano los precios de las obras y un beneficio económico que apenas servía para sufragar los gastos de alquiler del espacio. Con todo, la experiencia mereció la pena para él por haber conocido a Antonio Nogales y Márquez del Prado, quien le propuso pronunciar una conferencia sobre su obra — celebrada allí mismo días después $-{ }^{89}$ y con quien trabó de inmediato una cordialísima amistad.

La recepción de la muestra tampoco se caracterizó por el número o la enjundia de las críticas, y prácticamente se redujo a los comentarios de Láinez Alcalá y Prados López. El primero destacaba la "noble factura y trayectoria bien acusada en el aprendizaje y la superación del oficio palpitantes de muy honda emoción", "el feliz hallazgo de tan hondas realidades, poéticamente captadas" en "cuadros a los que no podemos llamar naturalezas muertas, porque allí los vemos vivos y bien vivos", "dignos de anotarse por su verismo bien manejado" y sus "singularísimas calidades plásticas". ${ }^{\circ} \mathrm{El}$ segundo, en un ejercicio de autobombo habitual en su labor desde los micrófonos de Radio Espańa de Madrid, habla de él como un artista que "no puede estar cuadriculado en escuelas clásicas ni modernas; es un pintor que se renueva, que vibra, que siente, que trabaja pensando siempre en el mañana", cargado de "la ponderación y del equilibrio más dignos de elogio", de lo cual "nace una manera personal de expresión, iluminada por la inquietud, por una auténtica inquietud" - para seguir con los temas... - "que colabora con un oficio madurado y reflexionado, sujeto a reglas básicas, a leyes inexorables que tantos abandonan y soslayan, sin perjuicio de creerse genios". ${ }^{91}$

Cada uno a su modo, ambos exégetas comparten una visión diacrónica sobre la pureza de su evolución artística: así, si uno afirma que "Moreno Sanjuán ha recorrido el amplísimo camino del mejor realismo pictórico españolista $[\ldots]$ que asciende desde la entraña palpitante de una pincelada diestra, bien aprendida y muy bien elaborada" por medio de obras "con tal sinceridad

89. $A B C, \mathrm{I} 4$ de diciembre de I949, 2 I.

90. Véase de nuevo el documento RLA-D-3I-I-38.

9I. Prados López, “Exposición Adolfo Moreno Sanjuán”, en su Tomo II, I2I-I22. 
5. Adolfo Moreno Sanjuán, Copla, s.f.

(ca. 1949). En el reverso de la tarjeta indica: "Copla. Adolfo Moreno

Sanjuán. Exposición

Galería Pereantón”. Reproducción conservada en el Archivo Rafael Láinez Alcalá del Instituto de Estudios Giennenses, original en paradero desconocido.

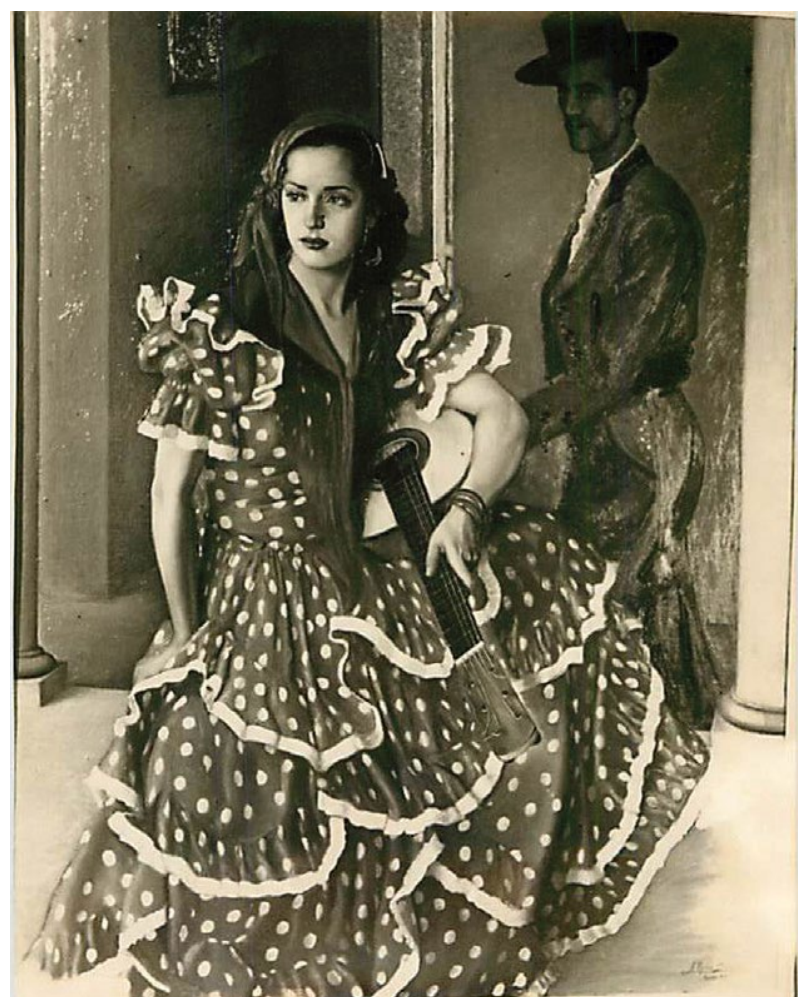

expuestas", el otro "que desde los cuadros pintados en el año 34 hasta éstos, aún frescos de emoción y de materia, ha recorrido un camino espinoso de luchas, de sueños, de dificultades" —insiste— "buscando lo mejor, para superarse y mantenerse en esa senda de juventud que ambiciona lo verdadero, como un ideal de vida", y aun más, que "se adapta y se modifica en su concepto y en su técnica, haciendo mil cálculos para decir su verdad" y que "ha revolucionado su paleta cromática y dibujísticamente ha echado a andar hacia horizontes insospechados, llevando como escudo la verdad" porque "la inquietud no es patrimonio ni de la edad ni de ninguna escuela artística; lo es de las almas honradas y sinceras que buscan la verdad". Una tercera crítica, firmada por M. Ferrara en su sección "Las manos creadoras" de Pueblo, vuelve sobre la forma y sentencia: "la figura sólo alcanza un tono de discreción tolerable", "los retratos son grises e inanimados, monótonos de color e inseguros de eje- 


\section{DOI: https://doi.org/10.22201/iie.18703062e.2021.119.2757}

I32

PABLO ALLEPUZ GARCíA

cución", "mejora notablemente en sus bodegones y flores" y "es muy importante deshacer lo hecho cuando no sale bien"..$^{92}$ Todos coinciden de manera bastante precisa con el relato retrospectivo que Adolfo hace en sus memorias, hasta el punto de abrir la conjetura de si las críticas se basan en conversaciones previas con él o si es él quien contrae tan importante deuda intelectual con aquéllas.

Ni la exposición ni la repercusión generada sirvieron de todas formas para relanzar su carrera, que por el contrario acentuó el declive debido a distintos problemas de salud: en mayo de I95I se fracturó el fémur de la pierna derecha — que ya tenía maltrecho desde nińo-y pasó en el sanatorio más de un año, en marzo de 1955 sufrió un grave desprendimiento de retina que le dejó totalmente incapacitado del ojo derecho, a principios de 1958 recayó de un fuerte ataque de reumatismo infeccioso que le mantuvo enclaustrado durante un buen tiempo; así pues, con menos tiempo libre todavía, perdida la percepción de la distancia y con serias dificultades para moverse, le costaba grandes esfuerzos mantener su progresión artística y apenas pensaba ya en participar en ningún evento. Dadas las circunstancias, tomó la determinación de comunicar su baja definitiva de la Asociación, lo cual le granjeó en lo sucesivo la enemistad declarada del secretario Prados López. ${ }^{93}$

El último acontecimiento reseñable en la vida artística de Adolfo se produjo en 1958 a propósito de una convocatoria de Fomento de las Artes Españolas (FAE) para la Exposición Permanente de Arte Contemporáneo. ${ }^{94}$ Cuando por fin se recuperó de sus achaques, en marzo de 1959, pasó por las salas para ver sus dos obras, probablemente recicladas o inspiradas en propuestas anteriores: la primera, Jarro con cardos, la encontró con facilidad en la galería principal — dominada por un Daniel Vázquez Díaz - entre las de mayor calidad, pero junto a otra muy estridente que acaparaba todas las miradas; la segunda, $L a$ modelo se ilustra (Sinfonía de gamas frías), no la encontró por ninguna parte y dio por hecho que no la habían colgado. Por casualidad y con algo de fortuna, un empleado le indicó que su bodegón y su desnudo ocupaban espacios distintos de la exposición, y que éste tenía que buscarlo en la sala de honor junto a las firmas de Julio Moisés o Francisco Soria Aedo, entre otros; "a pesar de hallarse en tan íntima compañía de los de los pintores ya consagrados y recom-

92. M. Ferrara, “Adolfo Moreno Sanjuán”, Pueblo, Madrid, I4 de diciembre de 1949.

93. Moreno Sanjuán, Memorias biográficas, 48-50.

94. Moreno Sanjuán, Memorias biográficas, 50-53. 
pensados, no se desluce; por el contrario, gana”, y no en vano faE le solicitó la renovación para siguientes ediciones.

Este pasaje funciona como correlato simétrico del de la inauguración del Salón de 1946, con una diferencia fundamental: si entonces mantenía la esperanza de encontrar sus obras hasta el último momento y terminó por frustrar sus expectativas, en esta segunda ocasión asumía de partida que no la hubieran colgado y se vio sorprendido por su colocación privilegiada; de alguna manera - siempre en el terreno de la implicatura- Adolfo lo presenta como la humilde recompensa final a toda una trayectoria, esto es, como un último acto de justicia poética no demandado, pero sí merecido. Y es que, con esto, prácticamente termina su carrera: durante los meses siguientes pintó algún cuadro más; en mayo de 196I el Dr. Barraquer lo operó en Barcelona de glaucoma en el otro ojo, a principios de 1964 escribió sus Memorias y el 29 de enero de 1965 murió en su domicilio a causa de una arterioesclerosis senil.95

\section{Un contramodelo autobiográfico: de la autocritica del oficio al oficio de la autocritica}

Más de medio siglo después, esas Memorias biográficas del pintor Adolfo Moreno Sanjuán (fig. 6) escapan por sorpresa a las dinámicas de la literatura gris y posibilitan la reconstrucción minuciosa de la trayectoria de su autor. Se trata de un documento inédito de apenas $18 \times$ I3 centímetros, al margen de cualquier canal de distribución, encuadernación rústica holandesa artesanal y un mecanografiado - con algunas correcciones a mano en tinta azul- que amenaza con borrarse. Las motivaciones para abordar dicha tarea por parte de un hombre que dos décadas antes había sido destinado a otro puesto porque no sabía escribir a máquina, ${ }^{96}$ y que no tenía descendencia directa seguirán siendo un misterio. A lo largo de siete capítulos, Adolfo narra para un destinatario incógnito —acaso él mismo, sin más - la infancia en provincias, la adaptación a Madrid, el periodo de formación en la Escuela, las complejidades de compaginar el trabajo en el Ministerio con la vocación artística, los sinsabores en diversos eventos culturales, el desarrollo de su única exposición individual y el agridulce final de su carrera, todo lo cual constituye un compendio de situaciones muy

95. Registro Civil de Chamberí, leg. II85, 92.

96. AGmitma, leg. 606I, "Comunicación de 9 de mayo de 1947 ". 
DOI: https://doi.org/10.22201/iie.18703062e.2021.119.2757

I34

PABLO ALLEPUZ GARCÍA

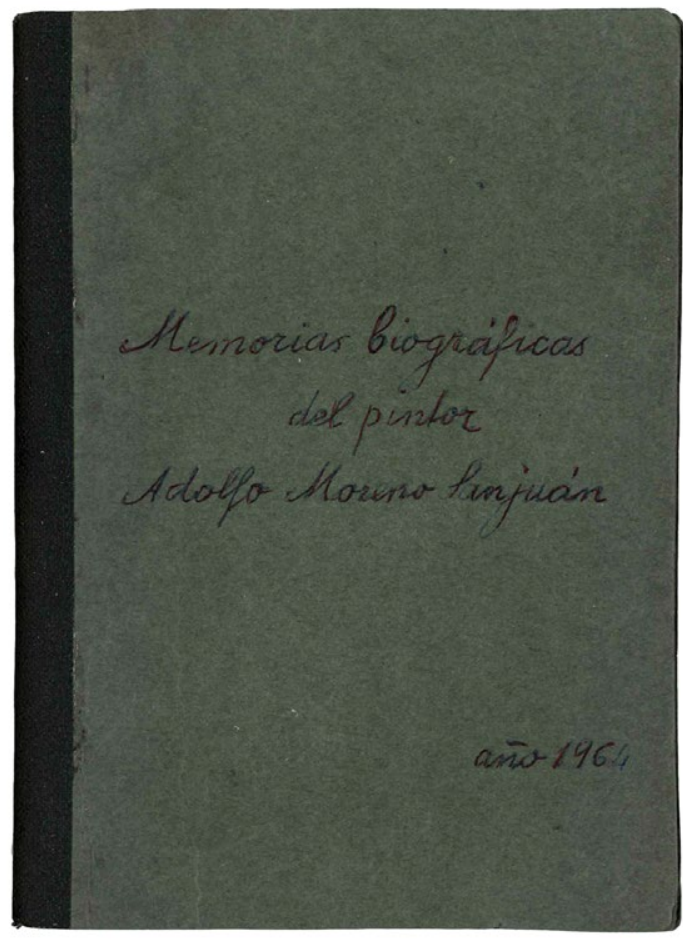

6. Cubierta de las Memorias biográficas del pintor Adolfo Moreno Sanjuán, 1964. Colección particular.

comunes a los artistas de cualquier época pero muy poco evidenciadas en el constructo de la Historia del Arte. Precisamente ahí reside un núcleo de fallos y fallas, derivado de las limitaciones metodológicas de la disciplina: los datos objetivos contenidos en su relato pueden carecer casi por completo de interés, y en consecuencia descartarse sin ulteriores consideraciones, pero la elaboración discursiva de esos datos aporta en sí misma una perspectiva con multitud de matices, aunque para desentrańarlos sea necesario adoptar procedimientos interdisciplinares. ${ }^{97}$

Algunos artistas autobiógrafos juegan la baza de la modestia — falsa o nomediante la clásica fórmula retórica de la captación de benevolencia cuando se

97. Véase el apartado "Dimensión literaria, dimensión histórica”, en José María Pozuelo Yvancos, De la autobiografía. Teoría y estilos (Barcelona: Crítica, 2005), I50-154; también, Susannah Radstone, "Working with Memory: an Introduction”, en su Memory and Methodology (Londres y Nueva York: Bloomsbury, 2000), I-22. 


\section{DOI: https://doi.org/10.22201/iie.18703062e.2021.119.2757}

sienten obligados a justificar su incursión en el memorialismo: Fernando Álvarez de Sotomayor, José Nogué Massó o Manuel Carmona de la Puente se escudan en la magnitud de las personas y los hechos que han conocido como testigos directos de sus respectivas generaciones; Eugenio Hermoso pide perdón por sacar a colación chascarrillos ajenos a la sencillez de su vida para hacerla más amena; Bernardino de Pantorba adelanta que se ahorrará las noticias biográficas sin importancia para centrarse en el origen de su pseudónimo; Santiago Ontañón desea permanecer al margen para dejar espacio a los otros; $9^{8}$ muchos de ellos incluso enuncian una disculpa inicial para excusar su diletantismo literario por su condición de artistas plásticos. ${ }^{99}$ Adolfo Moreno Sanjuán, en cambio, no recurre a ninguna de esas estrategias, pues era plenamente consciente de que su vida, en general, y su vida profesional, en particular, no habían alcanzado la notoriedad suficiente.

Tanto es así que decidió incluir un "resumen" a modo de epílogo en el cual reconoce con una sinceridad pasmosa que su producción pictórica había sido "corta o escasa y en parte, sin valor alguno interesante", que durante la década de 1925 a 1935 pudo trabajar con más regularidad y sus cuadros fueron adquiriendo poco a poco "si no excelencias, y mucho menos reflejos de genialidad, sí firmeza y valoración de luz y calidades; de dibujo, color y profundidad o volumen" hasta el punto de poderlos presentar "sin miedo a causar indignación ni provocar a nadie, por osados o pedantes, o hacer reír, ante la bobada inocente"; aun más, que nunca se ha dado tono "como pintor, ni como nada — verdad, que jamás hubo motivo-, pero ni siquiera en la edad en que se sueńa a todas horas, dormido en las ilusiones y en la inexperiencia" porque siempre tuvo pánico al ridículo, y que tras desviarse del camino del arte por su trabajo en el Ministerio no pretendió más que estudiar y superarse para su satisfacción, pero

98. Álvarez de Sotomayor, "Recuerdos de un viejo pintor”, I9; José Nogué Massó, Memorias de un pintor. La pintura española en el cambio del siglo XIX al XX (Tarragona: Museu d'Art-Diputació de Tarragona, 1993), I8-19; Manuel Carmona de la Puente, Todo lo vivido (Málaga: Centro Cultural de la Generación del 27, 200I), I3, I35 y I43; Francisco Teodoro de Nertóbriga, Vida de Eugenio Hermoso (Madrid: Tall. Graf. de Castilla, 1955), 48; Bernardino de Pantorba, Cómo, cuándo, dónde, por qué y para qué nació Bernardino de Pantorba (Madrid: Graf. Nebrija, 1977), 9; Santiago Ontañón González, Unos pocos amigos verdaderos (Madrid: Fundación Banco Exterior, 1988), I6.

99. Álvarez de Sotomayor, "Recuerdos de un viejo pintor", I9; Nertóbriga, Vida de Eugenio Hermoso, I2 y 737; Victorio Macho Rogado, Memorias (Madrid: G. del Toro, I972), 9-II; Carmona de la Puente, Todo lo vivido, Io; Amalia Avia, De puertas adentro. Memorias (Madrid: Taurus, 2004), 9 . 


\title{
DOI: https://doi.org/10.22201/iie.18703062e.2021.119.2757
}

\author{
I36 PABLO ALLEPUZ GARCÍA
}

sin soberbia, dispuesto a aprender con cada obra hasta de las opiniones profanas de los retratados.

$\mathrm{Y}$, sin embargo, contra todo pronóstico, decidió redactar unas "memorias biográficas", que nada tienen que ver con las de pintores extraordinarios que remedara William Beckford. “¿Por qué?”, parece uno preguntarse de inmediato; " $¿ y$ por qué no?", puede otro rebatir perfectamente. Por todas partes en el texto emana la convicción de que esas vidas ordinarias importan y merecen también ser narradas, porque de lo contrario quedarían fuera de los relatos oficiales de la Historia y se perderían para siempre. Contra ese olvido absoluto, la autobiografía de Adolfo funciona como un mensaje en la botella para reclamar su voz y poner en valor su apuesta vital, esto es, para dar cuenta de otros modos de pertenencia al mundo del arte que no necesariamente pasaban por el éxito. ${ }^{100}$

Tal atrevimiento desafía de entrada las convenciones del género, quizá incluso sin haber premeditado la transgresión que implica: no es ni un monarca, ni un aristócrata, ni un militar, ni un político, ni un escritor, tal vez ni siquiera un artista en sentido estricto, por cuanto al final se vio forzado a renunciar al ejercicio profesional de la pintura para ganarse un sueldo como funcionario; aun así, en lugar de centrarse en otros aspectos como su familia, sus dos matrimonios, sus amistades, sus afinidades políticas o sus inquietudes de cualquier tipo, lo hace empeñado en definirse como pintor malogrado y en desplegar una "autocrítica del oficio" que para el lector empático resulta exasperante y descorazonadora por igual. Y es que la selección del material biografiable compone una decidida historia de fracaso, que de tan normal resulta insólita en tanto que autobiográfica.

La última sentencia de las Memorias, que pudiera pasar desapercibida por el pusilánime tono general, introduce, no obstante, un giro decisivo:

mi pintura, que es esencialmente realista, lo es también modesta y clara; sin ningún truco ni estridencias; sencilla, honrada y sincera, como deseo serlo yo en todos mis actos, si consigo que a ellos alcance mi voluntad, y primero, mi consciencia. Por todo ello califico mi pintura de discreta. ${ }^{\text {ror }}$

ıoo. Véase Alan Bowness, The Conditions of Success. How the Modern Artist Rises to Fame (Londres: Thames \& Hudson, 1989).

IOI. Moreno Sanjuán, Memorias biográficas, 55-56. 
De la misma manera que en la genealogía compartida de la monografía y la novela del artista las manifestaciones creativas cumplen un papel como lugar de revelación, de toma de conciencia política, de performatividad sexual, en suma como ámbito de autoexploración, en este caso la dimensión estética deja de ser una mera anécdota para constituir un verdadero impulso, vehículo y reflejo de un proceso de subjetivación mucho más amplio, pero que por alguna razón prefiere subsumir dentro de lo pictórico; es decir, quizá esa obsesión por representarse como pintor no sea otra cosa que un gran circunloquio para reivindicarse a sí mismo como individuo, sin necesidad de entrar a valorar otros acontecimientos más delicados o controvertidos.

En línea con lo anterior, esa introspección externalizada se articula en torno a una defensa a ultranza de la retaguardia artística como garantía de sinceridad, por oposición a la supuesta deshonestidad de la vanguardia. Desde luego, semejante maniqueísmo no es novedoso ni mucho menos, pues buena parte de la literatura artística de la época reactualizaba la querella de los antiguos y los modernos en torno a la autonomía de la obra de arte, la función de la actividad artística o la formación técnica de los artistas, ${ }^{102}$ e incluso permeó en los escritos retrospectivos de Eugenio Hermoso, Luis Quintanilla o Victorio Macho, entre otros. ${ }^{103}$ Pero la inserción de esas tensiones en el ámbito de la autobiografía - espacio transicional entre las esferas pública y privada - ${ }^{104} \mathrm{y}$ la confrontación de fondo con el pacto referencial — contrato fundacional de las escrituras del yo- ${ }^{\text {ios }}$ desemboca, a su vez, en unas connotaciones específicas, de gran calado, que convierten ese aparente ejercicio estético prácticamente en un acto ético donde se negocian el compromiso social y la responsabilidad particular. ${ }^{106}$

IO2. Véase por ejemplo las múltiples intervenciones en la sección "La verdad y la máscara del arte nuevo" de La Estafeta Literaria o las conferencias pronunciadas en el curso de Enrique Azcoaga, Verdad y mentira del arte moderno (Madrid: Asociación Española de Críticos de Arte, 1985). Véase Brihuega, Las vanguardias; Jorge Luis Marzo y Patricia Mayayo, Arte en España (1939-2015). Ideas, prácticas, políticas (Madrid: Cátedra, 2015).

I03. Nertóbriga, Vida de Eugenio Hermoso, 7, 36-37, 203-204, 218, 251, 258-259, 269, 282, 437, 725; Luis Quintanilla Isasi, 'Pasatiempo'. La vida de un pintor (memorias) (A Coruña: Ediciós do Castro, 2004), 197-202; Macho Rogado, Memorias, 6I-63.

I04. Pedro Alonso García, La autobiografía como obra literaria. La vida secreta de Salvador Dali (Fráncfort del Meno: Peter Lang, 20I5), II8-I24.

I05. Véase Philippe Lejeune, "El pacto autobiográfico (1973)", en El pacto autobiográfico y otros estudios (Málaga: Megazul-Endymion, 1994), 49-87.

I06. Véase Ángel Loureiro, Huellas del otro. Ética de la autobiografía en la modernidad española (Madrid: Postmetropolis, 2016). 


\section{DOI: https://doi.org/10.22201/iie.18703062e.2021.119.2757}

I38

PABLO ALLEPUZ GARCÍA

A diferencia de la gran mayoría de sus colegas, y sin ningún tipo de pretensión teórica o retórica, Adolfo afronta el reto autobiográfico con la premisa de poner en cuestión su propia persona y lo lleva a cabo hasta las últimas consecuencias, pasando revista a sus timideces, sus inseguridades, sus miedos o sus incapacidades sin escamotear la autocrítica y aun en perjuicio de su imagen; una imagen personal y profesional que, sin embargo, no corre ningún riesgo, no sólo porque sus memorias se mantengan fuera de los cauces de distribución sino principalmente porque están construidas desde unos parámetros distintos, cuyos autobiografemas divergen del desarrollo tradicional y, por tanto, desestabilizan el horizonte de expectativas del lector.

En este sentido, su autobiografía supone todo lo contrario de una provocación como la Autopsia que promete Juanino Renau en el prólogo de sus Pasos $y$ sombras, sin llegar a cumplirla después a lo largo del relato, ${ }^{107} \mathrm{o}$ de un proyecto propagandístico como La vida secreta de Salvador Dali, en el cual los mitos y leyendas del artista se ponen al servicio de la construcción de un personaje genial; ${ }^{108}$ en el planteamiento de Moreno Sanjuán no hay espacio para malabares conceptuales, de manera que el origen humilde, la enfermedad infantil, el autodidactismo, las dificultades en la escuela o la incomprensión no terminan resignificándose para operar transformación alguna, sino que funcionan simplemente como constatación de los propios límites. Pero al mismo tiempo su autobiografía supone todo lo contrario también de los textos de otros artistas de segunda o tercera fila que parten desde una situación análoga a la suya —si no peor incluso-, como José Fernández Sánchez, José Ochoa Arias, Manuel Esteban Lamas o Rafael Orellano y Real de Osuna, ${ }^{109}$ y aun así replican ciertos moldes narrativos heredados de las biografías de los más excelentes pintores, escultores y arquitectos: en el discurso de Moreno Sanjuán tampoco hay lugar para el triunfalismo — siquiera relativo, en una escala más reduci-

I07. Juan Renau Berenguer, Pasos y sombras. Autopsia (México: Colección Aquelarre, 1953), 7-8; véase Carlos Martínez, Crónica de una emigración [La de los Republicanos Españoles en 1939] (México: Libro Mex Editores, 1959), 26I-262.

I08. Pablo Allepuz García, “¿Dalí joven, Dalí genial? Mitos y leyendas de artista en La vida secreta de Salvador Dali (1942)”, Goya. Revista de Arte, núm. 370 (2020): 48-63.

I09. José Fernández Sánchez, Memorias. Un cuarto de siglo con el arte (s.l.: Reunión Recreativa e Instructiva de Artesanos, 1967); José Ochoa Arias, Primeras memorias y biografía del pintor 'mineru' (Mieres: autoedición, 1984); Manuel Esteban Lamas, Confesiones de un niño tímido. Memorias de un pintor (Zamora: Semuret, 20II); Rafael Orellano y Real de Osuna, Son mis memorias reales (Valencia: BRS Levante, 20II). 


\section{DOI: https://doi.org/10.22201/iie.18703062e.2021.119.2757}

(AUTO)BIOGRAFÍA DE UN FRACASO: EL PINTOR-FUNCIONARIO

$\mathrm{da}$ - del recuento de las presencias en numerosas exposiciones, las pingües ventas de cuadros o las palabras de elogio por parte de la crítica.

La reversibilidad de la posición de Adolfo Moreno Sanjuán lo convierte en un caso crucial en el contexto español: mientras que su aportación como pintor puede ser considerada casi nula por no lograr diferenciarse de sus numerosos colegas, su contribución como autobiógrafo sí resulta significativa dentro de un corpus - el de la autobiografía de artista en España - caracterizado precisamente por potenciar la excepcionalidad del artista absoluto. ${ }^{\text {IIO }}$ Con todas las limitaciones y contradicciones susceptibles de identificarse en el texto, sus memorias ofrecen un contramodelo de autorrepresentación desde el cual revisar desde un punto de vista crítico dicho corpus y a partir del cual insistir en la necesidad de reescribir una historia del arte más reflexiva, más situada, más plural. En definitiva, la (auto)biografía del fracaso de Moreno Sanjuán señala una posible línea de debate para prevenir sobre ese otro fracaso que supondría dejar de cuestionar los fundamentos heurísticos, teóricos y metodológicos de la historiografía.

IIo. Catherine M. Soussloff, The Absolute Artist. The Historiography of a Concept (Mineápolis y Londres: University of Minnesota Press, 1997).

N.B. Este artículo es resultado de una ayuda del Ministerio de Educación, Cultura y Deporte (FPUi5/0602I). Además, se integra dentro del Proyecto de $\mathrm{I}+\mathrm{D}+\mathrm{i}$ "Rostros y rastros en las identidades del arte del franquismo y el exilio" (MCINN-AEI, ref. PID20I9-IO927IGB-Ioo), financiado por el Ministerio de Ciencia e Innovación, del que es I. P. Miguel Cabañas Bravo; y del Proyecto de I+D "Imaginarios de/en la Espańa contemporánea. Cultura material, identidad y performatividad" (Convocatoria Jóvenes Doctores UCM, ref. PR65/19-2242I), financiado por la Comunidad de Madrid y la Universidad Complutense de Madrid, del que es I. P. Alicia Fuentes Vega. 